\title{
Pancreatic Metastasis from Mixed Adenoneuroendocrine Carcinoma of the Uterine Cervix: A Case Report
}

\author{
Chihiro Nishimura $^{a}$ Hideaki Naoe $^{a}$ Shunpei Hashigo ${ }^{a}$ \\ Hideharu Tsutsumi $^{a}$ Shotaro Ishii ${ }^{a}$ Takeyasu Konoe $^{a}$ \\ Takehisa Watanabe $^{a}$ Takashi Shono $^{a}$ Kouichi Sakurai ${ }^{a}$ \\ Kiyomi Takaishi ${ }^{b}$ Yoshiaki Ikuta $^{c}$ Akira Chikamoto ${ }^{c}$ Motohiko Tanaka $^{a}$ \\ Ken-ichi Iyama ${ }^{d}$ Hideo Baba $^{c}$ Hidetaka Katabuchi ${ }^{b}$ Yutaka Sasaki ${ }^{a}$ \\ Departments of a Gastroenterology and Hepatology, ${ }^{b}$ Obsterics and Gynecology, \\ ${ }^{\mathrm{c} G a s t r o e n t e r o l o g i c a l ~ S u r g e r y ~ a n d ~}{ }^{\mathrm{d} S}$ Surgical Pathology, Faculty of Life Sciences, \\ Kumamoto University, Kumamoto, Japan
}

\section{Key Words}

Pancreatic metastasis - Uterine cervical mixed adenoneuroendocrine carcinoma .

Endoscopic ultrasonography-guided fine needle aspiration · Middle pancreatectomy

\begin{abstract}
Metastatic cancers of the pancreas are rare, accounting for approximately $2-4 \%$ of all pancreatic malignancies. Renal cell carcinoma is the most common solid tumor that metastasizes to the pancreas. Here, we present a case of uterine cervical carcinoma metastasizing to the pancreas and review the literature regarding this rare event. A 44-yearold woman with a uterine cervical tumor had undergone radical hysterectomy and had been diagnosed pathologically with stage Ib mixed adenoneuroendocrine carcinoma in 2004. She underwent concurrent radiotherapy and chemotherapy postoperatively. Pulmonary metastases subsequently appeared in 2008 and 2011, and she underwent complete resection of the lung tumors by video-assisted thoracic surgery. Although she was followed up without any treatment and with no other recurrences, positron emission tomography revealed an area of abnormal uptake within the pancreatic body in 2012. Enhanced computed tomography demonstrated a $20-\mathrm{mm}$ lesion in the pancreatic body and upstream pancreatic duct dilatation. Endoscopic ultrasonography-guided fine needle aspiration was performed and pathological examination suggested neuroendocrine carcinoma (NEC). On the basis of these results and the patient's oncological background, lesions in the pancreatic body were diagnosed as secondary metastasis from the cervical carcinoma that had been treated 8
\end{abstract}

Yutaka Sasaki

Department of Gastroenterology and Hepatology

Graduate School of Medical Sciences

Kumamoto University, Kumamoto 860-8556 (Japan)

E-Mailsasakiy@kumamoto-u.ac.jp 
Nishimura et al.: Pancreatic Metastasis from Mixed Adenoneuroendocrine Carcinoma of the Uterine Cervix: A Case Report

years earlier. No other distant metastases were visualized, and the patient subsequently underwent middle pancreatectomy. Pathological examination showed NEC consistent with pancreatic metastasis from the uterine cervical carcinoma. The patient has survived 7 months since the middle pancreatectomy without any signs of local recurrence or other metastatic lesions.

\section{Introduction}

Metastatic pancreatic cancers are rare neoplasms accounting for approximately 2-5\% of all pancreatic tumors [1-3]. The most common primary tumors giving rise to pancreatic metastases are renal cell carcinoma, lung cancer, breast cancer and colorectal carcinoma, followed by malignant melanoma, leiomyosarcoma and a large number of other neoplasms $[1,3]$. The median interval between resection of the primaries and detection of the metastasis is approximately 9 years $[2,4]$. In addition, since most patients do not present with related symptoms, detecting metastatic pancreatic tumors in the early stages is occasionally difficult. Currently, the role of surgery in the management of patients with metastatic pancreatic tumors is not clearly defined. Surgical resection is sometimes performed for metastatic pancreatic tumors, and the prognosis following surgical treatment of these tumors is reportedly better than that for primary pancreatic ductal adenocarcinoma [4]. The overall survival of patients who undergo pancreatic resection for metastatic disease appears dependent upon the pathological tumor type [4, 5]. In particular, in pancreatic metastases from renal cell carcinoma, long-term survival exceeding 10 years after surgery for the primary can be expected $[2,4]$.

Metastasis to the pancreas from uterine cervical cancer is extremely rare, and few cases have been reported to date [6-9]. We present herein a rare case of solitary pancreatic metastasis from cervical mixed adenoneuroendocrine carcinoma (MANEC) successfully treated with middle pancreatectomy. Interestingly, only the neuroendocrine component was observed in the metastatic lesion. This report discusses possible reasons for this outcome, along with a review of the literature.

\section{Case Report}

A 44-year-old woman had undergone radical hysterectomy and subsequent radiation therapy ( $50.4 \mathrm{~Gy}$ ) for cervical cancer 8 years before this presentation. The final pathological diagnosis was MANEC, comprising small cells with a high nucleus-to-cytoplasm ratio growing in a trabecular pattern (fig. 1a-f). Although the patient had been treated with oral chemotherapy using tegafur-uracil, small bilateral pulmonary nodules appeared after 3 years. Percutaneous computed tomography (CT)-guided needle biopsy and histopathological examination were performed, showing neuroendocrine carcinoma (NEC). Pathological findings were similar to those of the previous cervical carcinoma, and immunostaining for thyroid transcription factor-1 (TTF-1) yielded negative results. TTF-1 expression is specific for the lungs, thyroid and brain and is used as a reliable marker for distinguishing between primary lung carcinoma and metastases within the lungs. Given these findings, metastatic lung cancer from the earlier cervical cancer was diagnosed. Some lesions in the lungs disappeared following combined chemotherapy using nedaplatin (CDGP) plus irinotecan hydrochloride (CPT-11). For some remaining lesions in the right lung, video-assisted partial lung resection had been performed. After surgery, she was treated with additional chemo- 
Nishimura et al.: Pancreatic Metastasis from Mixed Adenoneuroendocrine Carcinoma of the Uterine Cervix: A Case Report

therapy (CDGP + CPT-11, paclitaxel + carboplatin, docetaxel hydrate + cyclophosphamide) and followed up with $\left({ }^{18} \mathrm{~F}\right)$ fluoro-2-deoxy-D-glucose positron emission tomography/CT (PET/CT) every 6 months. A small number of new lesions in the left lung diagnosed on CT were resected with video-assisted thoracic surgery and pathologically confirmed as metastasis from cervical NEC. One year after this lung operation, the patient was referred to our department when PET/CT showed abnormal uptake in the pancreatic body (fig. 2a, arrow) accompanied by slight back pain. Laboratory data on admission revealed no abnormalities in inflammation tests or tumor markers such as carcinoembryonic antigen, carbohydrate antigen (CA)19-9 and CA125. CT obtained in the arterial phase of enhancement showed a $20-\mathrm{mm}$ faintly attenuating homogeneous round mass located in the pancreatic body (fig. 2b, arrow). Endoscopic ultrasonography (EUS) revealed a wellcircumscribed hypoechoic mass (fig. 2c, arrow) in the pancreatic body and upstream pancreatic duct dilatation. Magnetic resonance cholangiopancreatography (MRCP) revealed stenosis of the main pancreatic duct in the pancreatic body (fig. $2 \mathrm{~d}$, arrow) and dilated upstream pancreatic ducts. Brush cytology specimens seen under endoscopic retrograde pancreatography and repeated pancreatic juice cytology specimens collected through an endoscopic nasopancreatic drainage tube were negative. EUS-guided fine needle aspiration (EUS-FNA) was therefore performed, resulting in a diagnosis of NEC. As no extrapancreatic disease was detected on imaging, middle pancreatectomy was performed. Postoperative pathological examination showed atypical cells derived from small to large neuroendocrine cells with a high nucleus-to-cytoplasm ratio growing in a trabecular to solid and nodular pattern under hematoxylin and eosin (HE) staining, as were seen in the patient's cervical and lung tumors (fig. 3a). Rosette formation was also observed (fig. 3b, arrow). High mitotic activity was seen, with 20 or more mitoses per 10 high-power fields (fig. 3c), along with positive immunostaining for synaptophysin (fig. 3d) and chromogranin A (fig. 3e) and negative results for TTF-1. The proliferative index indicated by MIB-1 was over $30 \%$ (fig. 3f). These results were compatible with secondary deposition from the cervical NEC. On the basis of the morphological features and results of immunohistochemical staining, metastatic pancreatic cancer from the cervical carcinoma was finally diagnosed. She has been followed up for 7 months since the surgery without any signs of local recurrence or other metastatic lesions.

\section{Discussion}

Metastatic pancreatic cancer is extremely rare, with a reported frequency ranging from 2 to $5 \%$ of all pancreatic malignant tumors $[1-3,8,9]$. Renal cell carcinoma is the most common solid tumor that metastasizes to the pancreas [1, 2, 8, 9]. In contrast, pancreatic involvement from cervical carcinoma is extremely rare. A PubMed database search found only 4 other reports of uterine cervical carcinoma metastasizing to the pancreas [6-9] (table 1). Most cases showed heterochronic metastasis and the interval between establishment of the primary diagnosis and metastasis varied from 11 months to 8 years. Of these, 2 cases were histologically identified as squamous cell carcinoma [6,9], whereas 2 other cases involved small cell carcinoma $[7,8]$. The present report is the first to describe MANEC as primary uterine cervical cancer metastasizing to the pancreas. A diagnosis of pancreatic metastasis is usually made based on imaging modalities such as ultrasonography, EUS, CT, MRI/MRCP and PET. The recent increased usage of EUS-FNA has made it possible to achieve pathological diagnosis before treatment $[8,10]$. In the current case, weak enhancement in the arterial phase and accompanying pancreatic ductal dilatations on CT were atypical 
findings for NEC. Brush cytology from the occlusive lesion of the main pancreatic duct seen under endoscopic retrograde pancreatography yielded negative results. Cytology performed on repeated pancreatic juice specimens taken from the endoscopic nasopancreatic drainage tube likewise yielded negative results. Consequently, the diagnosis of NEC was achieved by EUS-FNA.

Distinguishing primary pancreatic cancer and pancreatic metastases from other cancers arising elsewhere in the body is not easy. We diagnosed the pancreatic tumor preoperatively as metastatic disease based on the following observations. First, the tumor had not been detected on PET/CT 6 months earlier and the clinical course was too rapid for primary pancreatic NEC. Second, the patient had an oncological background and had undergone surgery for metastatic lung tumors 1 year earlier. In addition, postoperative pathological and immunohistological examinations identified NEC cells morphologically similar to cells of the cervical carcinoma which had been obtained 8 years earlier. We, therefore, finally diagnosed the pancreatic tumor as heterochronic pancreatic metastasis from uterine cervical carcinoma. Because no lymph node involvement had been detected over the course of 8 years, hematogenous spread was considered more likely than lymphatic spread.

Standardized treatment options for the management of patients with metastatic pancreatic tumors have yet to be clearly defined. In previous cases of metastatic pancreatic tumors from cervical uterine cancer, surgery was performed in all cases (table 1). In addition, longterm survival has been achieved in patients following resection of isolated metastasis to the pancreas $[2,4]$. Taken together, if the primary lesion can be successfully controlled and there is no evidence of other metastatic disease, surgical treatment of the metastatic pancreatic lesion should be considered. The metastatic lesion in this case was solitary and localized, with no other distant metastases. Therefore, the metastatic lesion was amenable to curative resection. Middle pancreatectomy was performed and the patient has so far survived 7 months since the surgery without local recurrence or other metastatic pancreatic lesions. Whereas the primary cervical tumor contained both adenocarcinomatous and NEC components, there was no sign of metastatic growth of adenocarcinoma in metastatic lung and pancreatic tumors. Clinical experience suggests that the neuroendocrine component in biliary MANEC behaves more aggressively than the regular adenocarcinomatous component $[11,12]$. In a recent review of MANEC in the gastrointestinal tract, some metastatic cases were described in which neuroendocrine components were detected in lymph nodes or liver foci [13]. These findings led us to speculate that only the NEC component without an adenocarcinomatous component might have metastasized to the pancreas in this case. NEC is a highly chemoresistant tumor associated with poor prognosis [14]. Since systemic chemotherapy had been administered in this case, another possible explanation is that the adenocarcinomatous component was successfully destroyed by the chemotherapy.

We have reported a rare case of metastatic pancreatic uterine cervical carcinoma. Metastatic pancreatic tumors should be considered in patients presenting with a pancreatic mass, particularly in those with a previous history of malignancy.

\section{References}

1 Ballarin R, Spaggiari M, Cautero N, De Ruvo N, Montalti R, Longo C, Pecchi A, Giacobazzi P, De Marco G, D'Amico G, Gerunda GE, Di Benedetto F: Pancreatic metastases from renal cell carcinoma: the state of the art. World J Gastroenterol 2011;17:4747-4756.

-2 Reddy S, Edil BH, Cameron JL, Pawlik TM, Herman JM, Gilson MM, Campbell KA, Schulick RD, Ahuja N, Wolfgang CL: Pancreatic resection of isolated metastases from nonpancreatic primary cancers. Ann Surg Oncol 2008;15:3199-3206. 


\section{Case Reports in Oncology}

\begin{tabular}{l|l}
\hline Case Rep Oncol 2013;6:256-262 \\
\hline DOI: $10.1159 / 000351308$ & $\begin{array}{l}\text { C 2013 S. Karger AG, Basel } \\
\text { www.karger.com/cro }\end{array}$ \\
\hline
\end{tabular}

Nishimura et al.: Pancreatic Metastasis from Mixed Adenoneuroendocrine Carcinoma of the Uterine Cervix: A Case Report

3 Tsitouridis I, Diamantopoulou A, Michaelides M, Arvanity M, Papaioannou S: Pancreatic metastases: CT and MRI findings. Diagn Interv Radiol 2010;16:45-51.

4 Eidt S, Jergas M, Schmidt R, Siedek M: Metastasis to the pancreas - an indication for pancreatic resection? Langenbecks Arch Surg 2007;392:539-542.

5 Reddy S, Wolfgang CL: The role of surgery in the management of isolated metastases to the pancreas. Lancet Oncol 2009;10:287-293.

6 Wastell C: A solitary secondary deposit in the pancreas from a carcinoma of the cervix. Postgrad Med J 1966;42:59-61.

7 Mackay B, Osborne BM, Wharton JT: Small cell tumor of cervix with neuroepithelial features: ultrastructural observations in two cases. Cancer 1979;43:1138-1145.

8 Kuwatani M, Kawakami H, Asaka M, Marukawa K, Matsuno Y, Hosaka M: Pancreatic metastasis from small cell carcinoma of the uterine cervix demonstrated by endoscopic ultrasonography-guided fine needle aspiration. Diagn Cytopathol 2008;36:840-842.

-9 Ogawa H, Tsujie M, Miyamoto A, Yasui M, Ikenaga M, Hirao M, Fujitani K, Mishima H, Tsujinaka T, Nakamori S: Isolated pancreatic metastasis from uterine cervical cancer: a case report. Pancreas 2011;40:797-798.

$>10$ DeWitt J, Jowell P, Leblanc J, McHenry L, McGreevy K, Cramer H, Volmar K, Sherman S, Gress F: EUS-guided FNA of pancreatic metastases: a multicenter experience. Gastrointest Endosc 2005;61:689-696.

11 Linder R, Dorfman T, Ben-Ishay 0, Kakiashvili E, Velodavsky E, Kluger Y: Mixed neuroendocrine tumor of the common bile duct. JOP 2013;14:71-73.

12 Harada K, Sato Y, Ikeda H, Hsu M, Igarashi S, Nakanuma Y: Notch1-Hes1 signalling axis in the tumourigenesis of biliary neuroendocrine tumours. J Clin Pathol 2013, E-pub ahead of print.

13 La Rosa S, Marando A, Sessa F, Capella C: Mixed adenoneuroendocrine carcinomas (MANECs) of the gastrointestinal tract: an update. Cancers 2012;4:11-30.

14 Olszewski U, Zeillinger R, Geissler K, Hamilton G: Genome-wide gene expression analysis of chemoresistant pulmonary carcinoid cells. Lung Cancer: Targets and Therapy 2010;1:107-117.

Table 1. Pancreatic metastasis from uterine cervical carcinoma

\begin{tabular}{|c|c|c|c|c|c|c|c|c|c|}
\hline \multirow{2}{*}{$\begin{array}{l}\text { Age } \\
\text { years }\end{array}$} & \multicolumn{2}{|l|}{ Primary } & \multicolumn{3}{|c|}{ Metastasis } & \multirow{2}{*}{$\begin{array}{l}\text { Interval to } \\
\text { metastasis }\end{array}$} & \multirow[t]{2}{*}{ Treatment } & \multirow[t]{2}{*}{ Outcome } & \multirow{2}{*}{$\begin{array}{l}\text { First authors } \\
\text { [Ref.] }\end{array}$} \\
\hline & histology & stage & site & $\mathrm{n}$ & $\begin{array}{l}\text { size } \\
\text { mm }\end{array}$ & & & & \\
\hline 66 & $\begin{array}{l}\text { squamous cell } \\
\text { carcinoma }\end{array}$ & II & head & 1 & 25 & 5 years & $\begin{array}{l}\text { pancreaticoduodenec- } \\
\text { tomy }\end{array}$ & died on POD 16 & Wastell [6] \\
\hline 48 & small cell carcinoma & NR & tail & 1 & 70 & concurrent & chemotherapy, BCG & NED at 3 months & Mackay [7] \\
\hline 38 & small cell carcinoma & IIb & body & 1 & 10 & 11 months & chemotherapy & NED at 5 months & Kuwatani [8] \\
\hline 45 & $\begin{array}{l}\text { squamous cell } \\
\text { carcinoma }\end{array}$ & NR & $\begin{array}{l}\text { body } \\
\text { tail }\end{array}$ & 1 & 80 & 2 years & $\begin{array}{l}\text { surgery, radiochemo- } \\
\text { therapy }\end{array}$ & $\begin{array}{l}\text { died } 8 \text { months } \\
\text { postoperatively }\end{array}$ & Ogawa [9] \\
\hline 44 & MANEC and NEC & $\mathrm{Ib}$ & body & 1 & 25 & $\begin{array}{l}8 \text { years ( } 1 \text { year } \\
\text { from latest lung } \\
\text { metastasis) }\end{array}$ & $\begin{array}{l}\text { middle pancreatecto- } \\
\text { my }\end{array}$ & NED at 7 months & our case \\
\hline
\end{tabular}

POD = Postoperative day; NR = not reported; NED = no evidence of disease; BCG= bacillus Calmette-Guérin. 


\section{Case Reports in Oncology}

\begin{tabular}{l|l}
\hline Case Rep Oncol 2013;6:256-262 \\
\hline DOI: $10.1159 / 000351308$ & $\begin{array}{l}\text { C 2013 S. Karger AG, Basel } \\
\text { www.karger.com/cro }\end{array}$ \\
\hline
\end{tabular}

Nishimura et al.: Pancreatic Metastasis from Mixed Adenoneuroendocrine Carcinoma of the Uterine Cervix: A Case Report
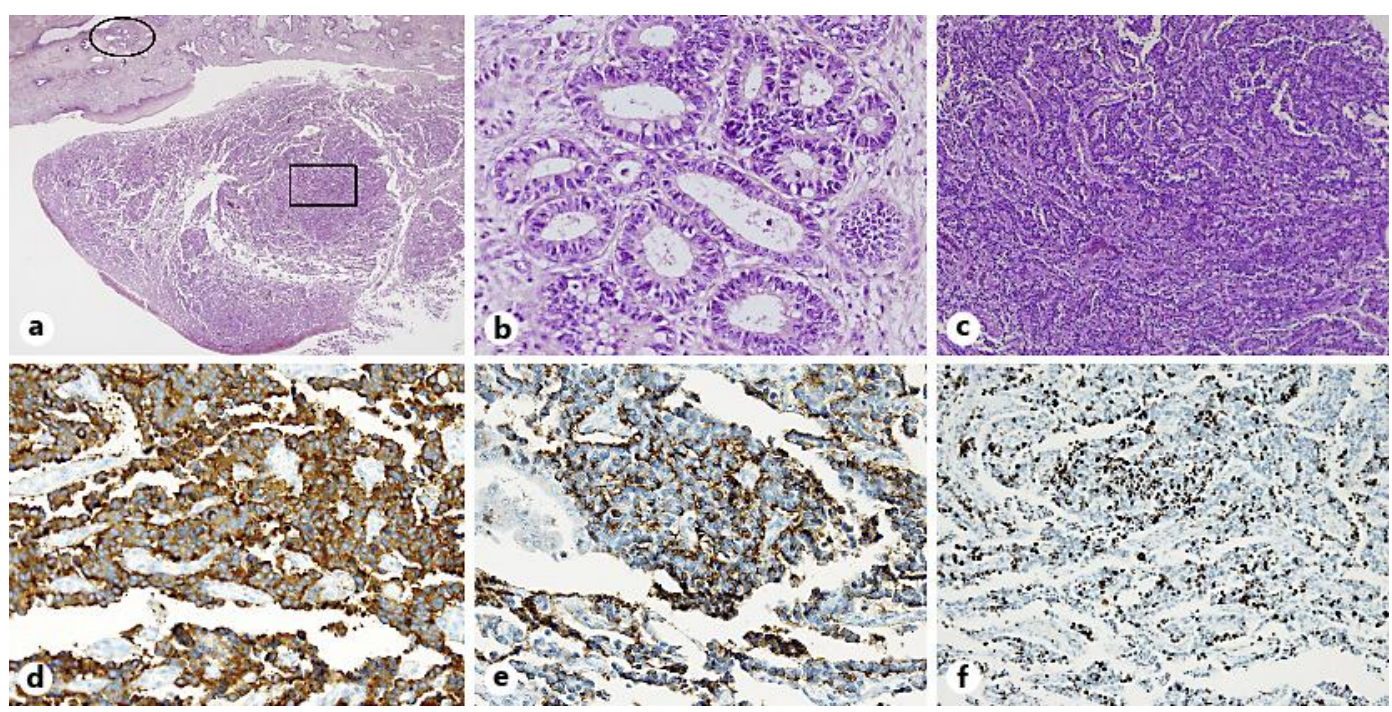

Fig. 1. Specimen removed from the uterine cervix shows MANEC. a Intimate admixture of adenocarcinoma and NEC. HE. $\times 12.5$. b Representative section of the tumor shows the adenocarcinoma component. A higher-magnification image of the oval area in a. HE. $\times 200$. c Representative section of the tumor showing the NEC component. A higher-magnification image of the rectangular area in a. HE. $\times 100$. d, e Tumor cells showing positive immunohistochemistry for synaptophysin, $\times 200$ (d) and chromogranin A, $\times 200$ (e). f MIB-1 proliferative index was approximately $25 \% . \times 100$.
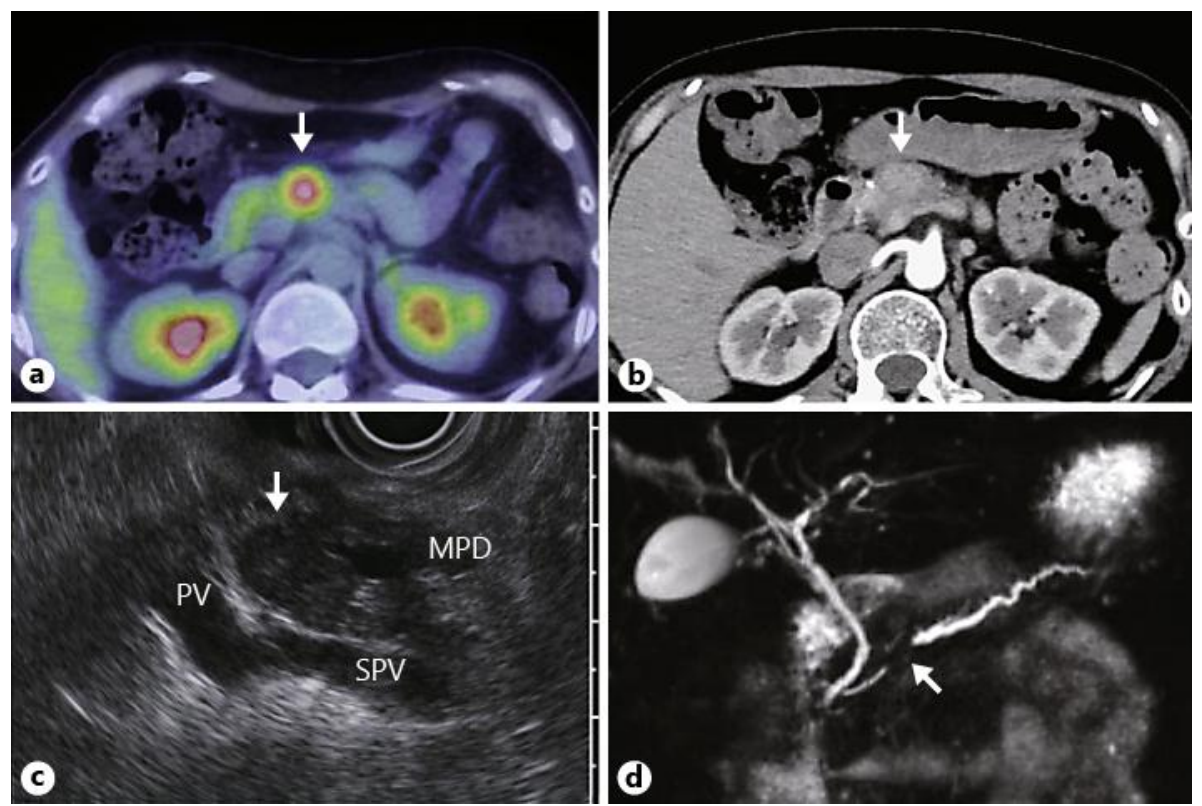

Fig. 2. Imaging diagnosis of a solitary tumor in the pancreatic body. a PET/CT showing abnormal uptake in pancreatic body (max. standardized uptake value, 3.1) (arrow). b Enhanced abdominal CT in the arterial phase, showing a faintly attenuating 20-mm round mass in the pancreatic body (arrow). c EUS revealing a well-circumscribed hypoechoic mass in the pancreatic body and accompanying upstream pancreatic duct dilatation (arrow). PV = Portal vein; SPV = splenic vein; MPD = main pancreatic duct. $\mathbf{d}$ MRCP reveals stenosis of the main pancreatic duct at the pancreatic body and dilated upstream pancreatic ducts (arrow). 


\section{Case Reports in Oncology}

\begin{tabular}{l|l}
\hline Case Rep Oncol 2013;6:256-262 \\
\hline DOI: $10.1159 / 000351308$ & $\begin{array}{l}\text { C 2013 S. Karger AG, Basel } \\
\text { www.karger.com/cro }\end{array}$ \\
\hline
\end{tabular}

Nishimura et al.: Pancreatic Metastasis from Mixed Adenoneuroendocrine Carcinoma of the Uterine Cervix: A Case Report

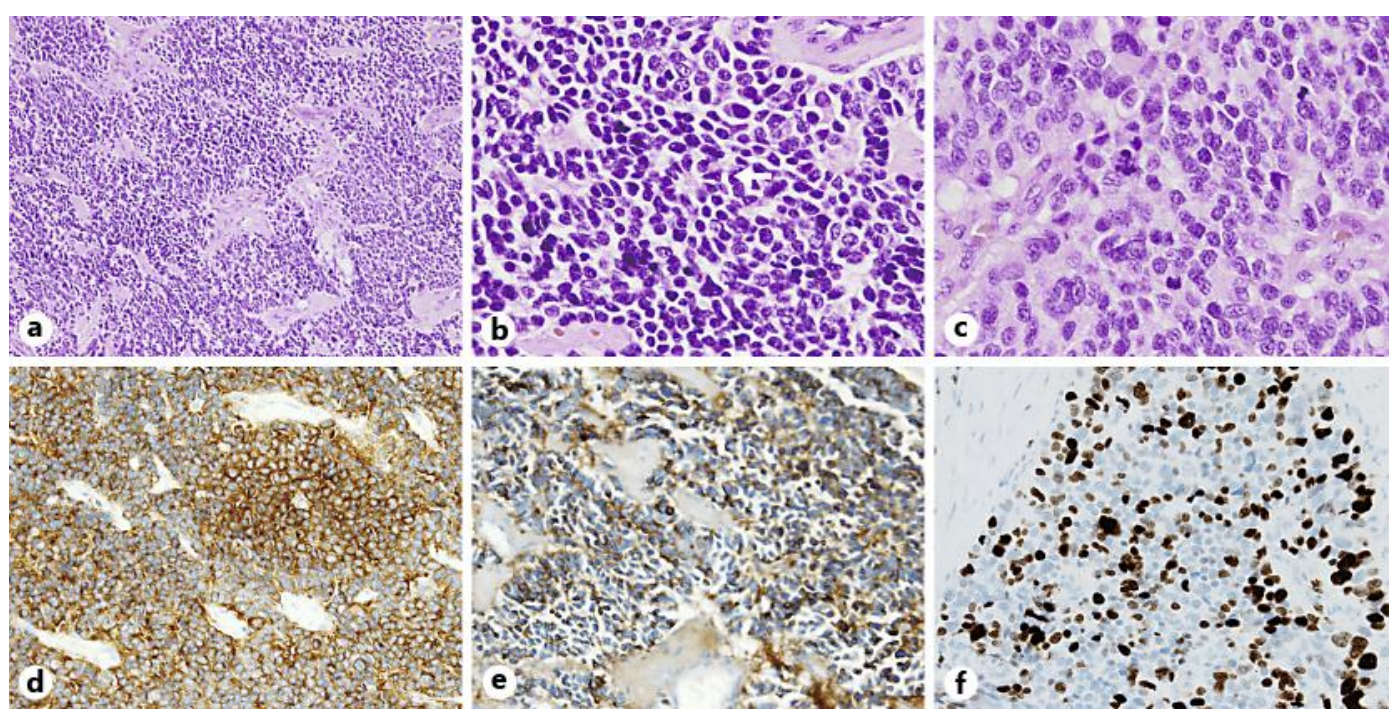

Fig. 3. NEC in the resected pancreatic tumor. a Carcinomatous growth patterns of neuroendocrine cells can be seen with HE staining. $\times 100$. b, $\mathbf{c}$ High-power view of the tumor demonstrates a rosette pattern (arrow), $\times 200$ (b) and solid pattern, $\times 400$ (c). d Synaptophysin staining of the solid area demonstrates endocrine carcinoma. $\times 200$. e Chromogranin A shows a similar pattern with less intense staining. $\times 200$. MIB-1 proliferative index was greater than $30 \%$. 